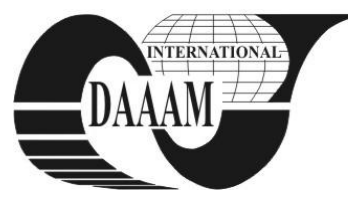

\title{
A COMPARISON BETWEEN THE TRANSVERSAL DISPLACEMENTS FIELDS, OF A LINEAR VISCOELASTIC CONNECTING ROD, WHICH IS IN VIBRATION OR IN REST
}

\author{
STANESCU, M[arius] M[arinel]; BAGNARU, D[an] G[heorghe]; BOLCU, D[umitru]; MIRITOIU, C[osmin] \\ M[ihai]; RIZESCU, S[abin] V[asile] \& DIACONU, I[lie]
}

\begin{abstract}
In this paper we make a comparison study between the field of the transversal displacements of a connecting rod (of bar type) part of a mechanism $R$ (RRT), kinematic element that has linear viscoelastic behavior, which is in aleatory vibrations, with the field of the transversal displacements for the same bar, but in rest, considered simply leaning. We shall demonstrate that the movement kinematical parameters lead to vibrations amplitude increase, which is why we have to take into account their influence over the displacements made by vibrations, when we design the mechanisms. Finally, we are comparing the theoretical results with the experimental ones.

Key words: vibrations, variational principle, displacements fields, connecting rod
\end{abstract}

\section{INTRODUCTION}

The researches conducted so far by various authors, have not made a comparison between cross-field displacements for a linear viscoelastic rod, which is in vibration and respectively at rest. We propose a novelty in the speciality literature, specifically, we have done the comparisons in similar circumstances, considering null initial conditions, for the bar in rest, as in the case of the rod from connection rod mechanism. It was necessary to assume that the bar (simply supported) is being subjected to a slight disturbance under the form of a constant force $\mathrm{f}=0,125[\mathrm{~N}]$.

It is noted that the amplitudes for transversal displacement, in the case of a linear viscoelastic bar at rest, are lower than those from the case of linear viscoelastic rod, for a connecting rod mechanism. In our future studies, we will analyze the same problem, only that the connecting rod is subjected to random vibrations.

\section{THEORETICAL RESULTS}

The mathematical model in the first approximation has the form (Bagnaru \& Marghitu, 2000; Bagnaru, 2005; Stanescu et al., 2009):

$$
\begin{aligned}
& {\left[L_{0}(s)\right]\left\{\tilde{u}^{(1)}\right\}+\rho A \cdot\left[\begin{array}{cc}
-1 & 0 \\
0 & 1
\end{array}\right]\left\{\tilde{a}_{0}\right\}+} \\
& +\rho A x \cdot\{\tilde{g}(s) ; \tilde{\varepsilon}(s)\}^{t}=\{0\} \\
& {\left[L_{0}(s)\right] \bullet=\tilde{E}(s) \cdot I \cdot\left[\begin{array}{ll}
0 & 0 \\
0 & 1
\end{array}\right] \frac{\partial^{4} \bullet}{\partial x^{4}}+} \\
& +\left[\begin{array}{cc}
\tilde{E}(s) \cdot A & 0 \\
0 & -\rho I s^{2}
\end{array}\right] \frac{\partial^{2} \bullet}{\partial x^{2}}+s^{2} \rho A\left[\begin{array}{cc}
-1 & 0 \\
0 & 1
\end{array}\right] \bullet \\
& \left\{\widetilde{a_{0}}\right\}=\left\{\widetilde{a_{01}}(s) ; \widetilde{a_{02}}(s)\right\}^{t} ; \omega^{2}(t)=g(t) ; \\
& \left\{\tilde{u}^{(1)}\right\}=\left\{\tilde{u}_{1}^{(1)}(x, s) ; \tilde{u}_{2}^{(1)}(x, s)\right\}^{t}
\end{aligned}
$$

$$
\begin{array}{r}
b_{0}=3 K+G ; \tilde{E}(s)=\frac{a_{0} s}{b_{0} s+b_{1}} ; a_{0}=9 G K ; \\
b_{1}=\frac{3 G K}{\eta} ; K=\frac{v E}{(1+v)(1-v)}+\frac{2}{3} G
\end{array}
$$

$\tilde{E}(s)$ has the expression corresponding to Maxwell mechanical model, specifically for plastics, $G$ is the transversal elasticity modulus, $\mathrm{K}$ is the compressibility modulus, $v$ is the transversal Poisson contraction coefficient and $\eta$ is the constant corresponding to Newtonian component of the Maxwell model.

For the bar in rest, by canceling kinematics parameters, (1) becomes:

$$
\left[L_{0}(s)\right]\left\{\tilde{u}^{(1)}\right\}+\{f\}=\{0\}
$$

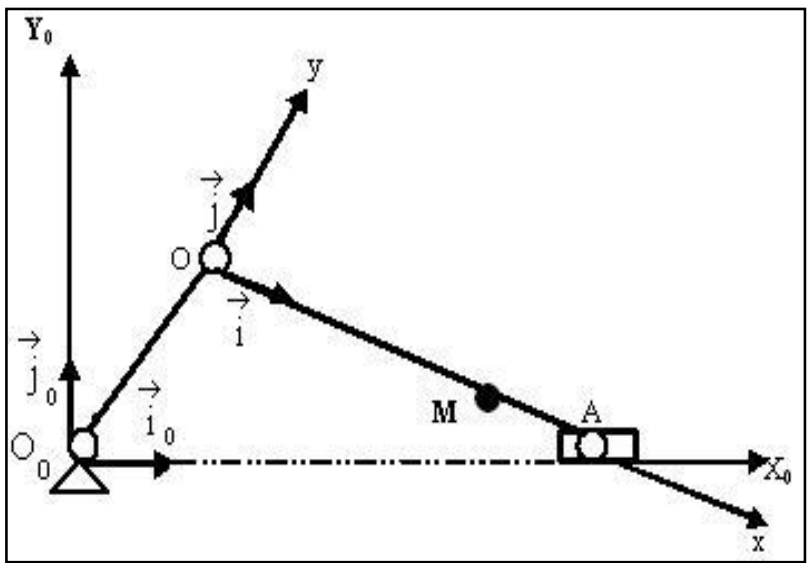

Fig. 1. R(RRT) Mechanism

\section{DISPLACEMENTS FIELD}

If we apply the finite Fourier transforms in (1) respectively in (2), and we only refer to transversal vibrations, we obtain some algebraic equations, having unknown the movements $u_{2, s}^{(1)}(n, t)$ in Laplace and Fourier images, finite in sinus.

Reversing the Laplace and Fourier transforms, the solutions in the first approximation $\left\{u^{(1)}(x, t)\right\}$ of the two equations (Harrison, 1997; Fu et al., 1997) result

$$
u_{2}^{(1)}(x, t)=\frac{2}{L} \sum_{n=1}^{\infty} u_{2, s}^{(1)}(n, t) \cdot \sin \left(\alpha_{n} \cdot x\right)
$$

where $u_{2, s}^{(1)}(n, t)$ are given in Bagnaru \& Marghitu-2000, and Bagnaru, 2005.

Let us consider the case in which $\mathrm{L}=1[\mathrm{~m}], \mathrm{b}=0,04[\mathrm{~m}], \mathrm{h}=$ $0,005[\mathrm{~m}], \mathrm{r}=0,07[\mathrm{~m}], \omega_{0}=157\left[\mathrm{~s}^{-1}\right], \rho=1285,7\left[\mathrm{~kg} / \mathrm{m}^{3}\right]$, $\mathrm{K}=8452,969[\mathrm{MPa}], \quad \eta=6,14 \cdot 10^{7}[\mathrm{MPa}], \quad \mathrm{G}=5071,782$ $[\mathrm{MPa}]$, the material being textolit. 
With the definition (3), and with the above concret dates, there result the graphic representations from figures 2 and 3.

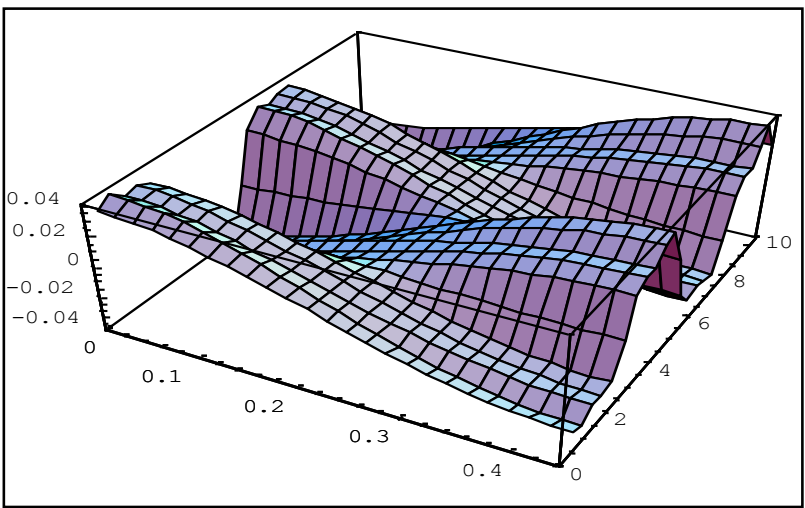

Fig. 2. Transversal displacement representation for viscoelastic $\operatorname{rod} \mathrm{OA}$

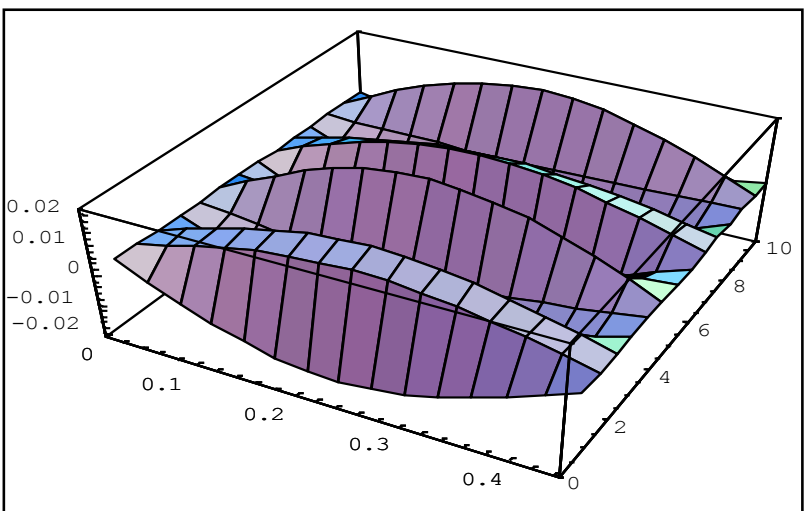

Fig. 3. Transversal displacement representation for viscoelastic rod OA simply supported and in rest

Next, we proceeded to experimental testing, in the purpose of comparing the theoretical results with the experimental ones.

\section{EXPERIMENTAL TESTS}

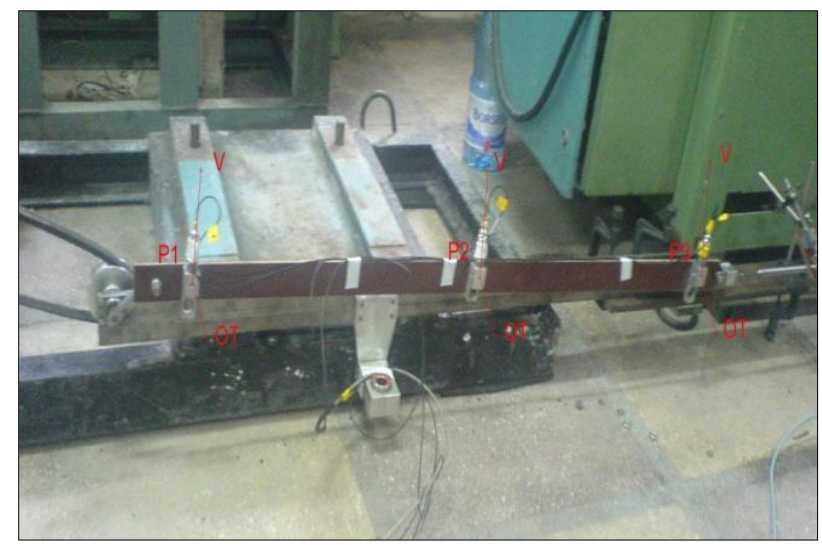

Fig. 4. The experimental montage

To determine the vibratory response, there were used three B \& K 4391 accelerometers mounted to $50[\mathrm{~mm}]$ of the drive end (point 1), the middle rod (point 2) and to $50[\mathrm{~mm}]$ by the end of the backstage operation (point 3), successively on vertical direction, and horizontal-transversal toward the plane for operating of the connecting rod (Fig. 4).

The connecting rod system was acted by a three-phase motor AC power of $25 \mathrm{~kW}$, with constant speed $1500[\mathrm{rpm}]$, through a variator with friction, so that at the level of the connecting rod, there could be realised the variable speed in range $60-240[\mathrm{rpm}]$.

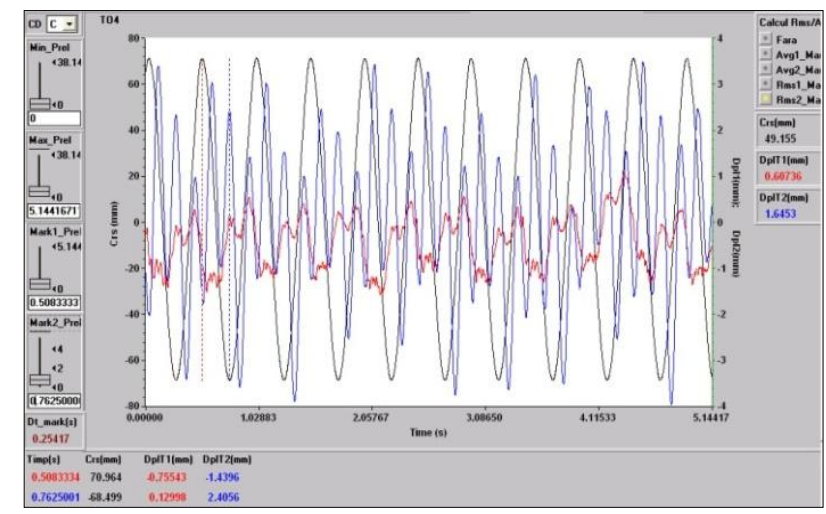

Fig.5. The variation diagram of the transversal displacement in the case of linear viscoelastic connecting rod

In Fig. 5, it is presented the diagram of variation in time, of the transversal displacement, in the case of linear viscoelastic connecting rod, part of the mechanism from Fig. 1.

Calculating the error with the relation:

$$
\varepsilon=\frac{\left|u_{2}^{t}-u_{2}^{e}\right|}{u_{2}^{\max }}
$$

where $u_{2}^{t}$ and $u_{2}^{e}$ are the theoretical and experimental values of the displacement $\left(u_{2}^{\max }=\max \left\{u_{2}^{t} ; u_{2}^{e}\right\}\right)$, we obtained errors $\varepsilon<10 \%$, which are allowed in technique, due to the clearances from kinematical couplings, and the vibrations transmitted through basis and approximate methods that we used.

\section{CONCLUSIONS}

The elements that were presented above show that the kinematical parameters of movement lead to increased vibration amplitudes, wherefore, it is necessary, as in the case of mechanisms design, to take into account the influence of kinematics parameters of the movement at the displacements caused by existing of the vibrations.

\section{ACKNOWLEDGMENT}

This work was partially supported by the strategic grant POSDRU/88/1.5/S/50783 (2009), co-financed by the European Social Fund - Investing in People, within the Sectoral Operational Programme Human Resources Development 20072013.

\section{REFERENCES}

Bagnaru, D., Marghitu, D.B. (2000). Linear Vibrations of Viscoelastic Links, 20th Southeastern Conference on Theoretical and Applied Mechanics (SECTAM-XX), April 16-18, Callaway Gardens and Resort, Pine Mountain, Georgia, USA, p. 1-7

Bagnaru, D. (2005). The vibrations of kinematic elements, SITECH Publishers, Craiova, 170 p., ISBN 973-657-854-2

Harrison, H.R. (1997). Advanced Engineering Dynamics, John Wiley \& Sons Inc., New York

Stanescu, M.-M., Chelu, A., Nanu, Ghe., Bagnaru, D., Bolcu, D., Cuta, P. (2009), Influence of kinematic parameters on the deterministic vibrations of the viscoelastic linear connecting rod, part of a rod lug mechanism, Annals of DAAAM, 20(1), p. 837-839

Fu, K.S., Gonzalez, R.C. \& Lee, C.S.G. (1997). Robotics, McGraw-Hill. 